\title{
Waste cooking oil as an energy resource: review of Chinese policies
}

Article

Accepted Version

Zhang, H., Wang, Q. and Mortimer, S. R. (2012) Waste cooking oil as an energy resource: review of Chinese policies. Renewable and Sustainable Energy Reviews, 16 (7). pp. 52255231. ISSN 1364-0321 doi: https://doi.org/10.1016/j.rser.2012.05.008 Available at https://centaur.reading.ac.uk/30879/

It is advisable to refer to the publisher's version if you intend to cite from the work. See Guidance on citing.

To link to this article DOI: http://dx.doi.org/10.1016/j.rser.2012.05.008

Publisher: Elsevier

All outputs in CentAUR are protected by Intellectual Property Rights law, including copyright law. Copyright and IPR is retained by the creators or other copyright holders. Terms and conditions for use of this material are defined in the End User Agreement.

\section{www.reading.ac.uk/centaur}

\section{CentAUR}

Central Archive at the University of Reading 
Reading's research outputs online 


\title{
Waste Cooking Oil as an Energy Resource: Review of Chinese Policies
}

\author{
Huiming Zhang ${ }^{\mathrm{a}, \mathrm{b} *} \quad$ Simon R. Mortimer $^{\mathrm{c}} \quad$ Qunwei Wang $^{\mathrm{d}}$ \\ a College of Economics and Management, Nanjing University of Information Science \& Technology, Nanjing, \\ 210044, China \\ b China Institute of Manufacturing Development, Nanjing University of Information Science \& Technology, \\ Nanjing, 210044, China \\ c Centre for Agri-Environmental Research, University of Reading, Earley Gate, PO Box 237, Reading RG6 6AR, \\ United Kingdom \\ d School of Dongwu Business, Soochow University, Suzhou, 215021, China
}

\begin{abstract}
Converting waste cooking oil into biofuel represents a three-win solution, dealing simultaneously with food security, pollution, and energy security. In this paper, we encode the policy documents of waste cooking oil refining biofuel in China based on content analysis, and explore the related policies from the two dimensions as basic policy tools and enterprises supply chain. Research indicates the weak institution coordination of policy issuing entities. Also, the findings show that tools of regulatory control and goal planning are overused. Policies of government procurement, outsourcing and biofuel consumption are relatively scarce. Generally, government focuses more on formulating policies from the strategic, administrative and regulatory aspects, while less on market-oriented initiatives as funding input and financial support.
\end{abstract}

Keywords: Waste cooking oil; biofuel; policy tools; content analysis 


\section{Introduction}

Waste cooking oil refers mainly to frying oil used at high temperatures, edible fat mixed in kitchen waste and oily waste water directly discharged into the sewer. China is the large producer of waste cooking oil, with 500 million tons of waste cooking oil produced each year in the catering industry of large and medium cities. If the waste is improperly handled, it will pollute the cities, as well as flow back to the dining tables in case of weak government supervisory, profit-driven practices and lack of rapid test. According to the statistics, China's waste cooking oil flowing back to the dining table amounts to 200-300 million tons, which poses a great health hazard to consumers [1]. Therefore disposal and reutilization of waste cooking oil is a long-term alarming problem in China.

As a solution of this problem, converting waste cooking oil into biofuel is a three-win alternative, dealing simultaneously with food security, pollution, and energy security. The world energy producing and consuming countries such as US, Japan, Brazil and Germany have enacted supporting policies.

Chinese government also gives great importance to the development of waste cooking oil disposal and biofuel. To process waste oil, China has promulgated Regulations on the Waste Cooking Oil Management for the Food Production and Business Operation Entities (2002), Emergency Notification of Preventing Entry of Waste Cooking Oil Entering Food \& Beverage Services (2010), Opinions on Strengthening Management of Kitchen Waste and Drainage Oil (2010), successively. As for the exploitation of biofuel, China launched the Tenth Five-year Programme for National Key Technology Research and Development in 2004. In January 2006, Renewable Energy Law was implemented, which was designed to encourage the production and use of bio-liquid fuel. In the same year in September, the Ministry of Finance, National Development and Reform Commission, the Ministry of Agriculture, the State Administration of Taxation,
The State Forestry Bureau jointly issued Proposals for Implementation of Tax Support Policy on Development of Bioenergy and Biochemical Industry, providing biofuel with financial and tax benefits.

Nevertheless, China still lags behind of developed countries in the waste oil refining biofuel. In the practice of biofuel enterprises, many problems such as shortage of raw material and sluggish sales need to be solved urgently. Meaningful work, sorting out and assessing relative policies systematically are the efficient way to solve this problem. Also, this is the logical starting point of the paper.

\section{Literature Review}

The research work related to the policies waste oil refining biofuel can be categorized as follows:

\subsection{Current situation of waste oil disposal or biofuel exploitation in China}

Based on the discussion of waste oil management experience in Jiangsu environmental protection department, Yu presented the defects of laws and regulations, functional responsibility demarcation and information system during the process of waste oil disposal. Finally Yu proposed the raw material supply policies to strengthen supervision at the source, enhancing social surveillance and resource comprehensive exploitation [2]. $\mathrm{Ni}$ investigated the current status of kitchen waste recycling industrialization, suggesting that government should improve food waste processing and management system, consummate industrial chain and increase the compensation for recycling [3]. Through a thorough survey of kitchen waste management in Tianjin, China, $\mathrm{Ji}$ proved the necessity of strengthening government-led, market regulation and legal supervision in order to recycle the kitchen waste [4]. $\mathrm{Wu}$ noted that incentives and construction of raw materials basis should be provided to reduce raw material costs [5]. Yang and $\mathrm{Ni}$ also attached importance to the development of biofuel. However, their findings proved that perfecting raw material system is an important measure for biodiesel 
industrialization [6]. Compared with above studies, some researchers integrated the issues of waste oil disposal and biofuel industrialization effectively. For example, Li and Wang elaborated the importance and feasibility of utilizing waste oil refining biodiesel, and suggested that government should improve the regulations of purchasing waste oil, and introduce biofuel producing subsidies. Also, China should handle administrative licensing and approval procedures of environmental, firefighting, safe production, meteorology and quality control actively for non-edible animal and vegetable oil sectors and biodiesel companies [7]. Similar viewpoint with $\mathrm{Li}$ and Wang, Ji deemed that waste oil should be fully used for the biofuel industrialization. According to Ji's study, government subsidies are critical to the promotion of biodiesel development [8]. Not taking into account of government subsidies, Zhang and $\mathrm{Ji}$ offered policies of exerting bio-liquid fuel potential from the perspective of industrial management, supply chain incentives and adaptive capacity of resource and technology [9] and [10].

A few studies analyzed the commercialization of raw material supply of biofuel. For instance, Wang, Wang and Zheng insisted on the importance of promoting industrialization and supporting private sectors development because non-food biofuel's commercialization requires substantial initial investments, advanced technology and strong market response capacity [11].

\subsection{Waste oil as an energy resource in foreign countries}

Tsai, Lin and Yeh presented an analysis of converting waste cooking oil into diesel in Taiwan, which especially focused on the environmental protection, economic and financial incentives [12]. Alexey, Arthur and Peter investigated biofuel resources potential, and discrepancy between biofuel potential and actual development through a case-study in the Russian Omsk region. The reasons for this discrepancy can be found in the low policy and institutional priority given to non-fossil fuel exploitation and lack of market opportunities [13]. Classifying individual countries into groups, Giovanni, Martin and Claudia mainly reviewed the blending targets, supporting schemes and feedstock use for biofuel production [14]. Providing specific recommended practices for ensuring fuel quality and year-round operability in the US, Grasman and Sadashivam proposed that federal and state incentives should be offered to stimulate the biodiesel market [15]. Basheer et al. analyzed the performance of biodiesel fuels obtained from used domestic waste oils in the US, Canada, Japan and Ireland etc. According to Basheer et al.'s review, $70 \%$ of the used cooking oil could be recovered from restaurants and other sources by providing adequate incentives. Consequently, the incentives for the initiative are necessary [16].

More scholars emphasized on the industrialization policies of biofuel in developed countries. For example, Han and Xue discussed the biofuel industrialization policies in South Korea and other countries with the track of raw material supplies, technology R\&D and marketing [17] and [18]. Taking the innovative and pioneering countries in the EU as research objectives, Tobias et al. stated that high biofuel consumption and new technology make it possible for the member states to take measures favoring specific types of biofuels. Therefore, the states should provide the subsidies for raw material, production facilities and user incentives [19].

Obviously, a certain amount of valuable research concerning the policies of waste cooking oil refining biofuel has been carried out. However, the policies directly related to waste oil refining biofuel are relatively scarce and mainly qualitative. Thus we employ content analysis, that is, collect and organize information source in standardized format, which can further be described and used for frequency statistics.

\section{Method}

Content analysis was initially proposed by National Office of US Assessment in 1983. The 
working procedure of this method is explained as follows: deciding whether this method should be adopted, determining which documents shall be included into content analysis, constructing policy dimensions, listing coding catalog and analyzing results. The advantage of content analysis is extracting new opinions from the historical data to support text analysis. Compared with qualitative approach, this method is more applicable to the policy texts analysis because of its foreseeability and guiding to the policy practice.

\section{$3 \mathrm{X}$-Y Dimension analysis framework}

Content analysis is started by selection of policy documents and construction of policy dimensions. Documents of waste cooking oil disposal and biofuel come from the Food Safety Quality website, and New and Renewable Energy website, respectively.

To ensure the reliability and representativeness of policy selection, it is necessary to filter the policy documents according to the following principles:

Firstly, issuing agencies are under the direct leadership of the State Council. Secondly, the documents manifest the governmental policies, including planning, opinions and measures, etc. Whereas, the documents such as industry standards are exempted. Thirdly, although some polices merely involve into waste cooking oil or biofuel disposal instead of effectively integrating the two, these polices have certain guiding significance for producing biofuel with waste cooking oil. Therefore these indirect policy documents are also incorporated into the analysis, and finally we get 34 effective texts (see Table 1).

To construct policy dimensions, it is necessary to give considerations to the association among the horizontal and longitudinal policies, thus we employ two dimensions of $\mathrm{X}-\mathrm{Y}$ to investigate policies of producing biofuel with waste cooking oil.

\subsection{1 $\mathrm{X}$ dimension: basic policy tool}

The The basic policy tool of $\mathrm{X}$ dimension locates at the fundamental layer of the policy system, indicating the basic element of policy tools. The policy effects can be realized by combining unit tool through inter-combination. Currently, the academia has not reached a consensus on classification of policy tools.

An adoptable classification in the western academia was proposed by Van der Doelen, who divided policy tools into three categories, including legal, economic and communication tools. The representative scholars in China are Zhang, Chen and Tao, etc. According to Zhang's research, policy tools contain loan and services directly provided by the governmental departments, contract outsourcing, subsidies, coupon, concession operation, voluntary service and market operation, etc. [20]. Chen classified policy tools into three categories: market tools, industrial and commercial management technologies and social measures [21]. Tao deemed that policy tools comprise of five aspects i.e. economic, administrative, management, political and social [22]. Although the scholars provided useful practices for analyzing policy tools, the classification of the policy tools at the present are non-specific or overlap one another. During the process of producing biofuel, it is critical to carry out policy supports such as subsidies, financial support and waste disposal, etc. Therefore, analogous to the idea of Rothwell and Zegveld [23], we categorize the policy tools as supply type, environmental type and demand type. Amongst these, supply and demand-typed policies directly act on the biofuel production process. The main difference between the two types of policies is that the former promotes the production factors supply with scientific technology information, education and fund input, while the latter lays emphasis on reducing the production uncertainties through governmental procurement, outsourcing and international cooperation. The environmental-typed policies mainly refer to indirect incentives as target planning, legal regulation, financial support, tax preference and intellectual property protection, etc., which are 
provided by government to facilitate the producing biofuel with waste cooking oil.

\subsubsection{Y dimension: enterprise value chain}

The comprehensive competitiveness of entire enterprise value chain determines enterprise competitiveness. For producing biofuel with waste cooking oil, the value chain includes four stages as R\&D of biofuel produced by waste cooking oil, recycling and disposal of waste cooking oil, biofuel production and marketing, among which, waste cooking oil detecting technique directly affects the kitchen waste flow direction. Under the circumstances of lacking advanced detection technique, the waste cooking oil may flow back to the dining table, resulting in the shortage supply of biofuel raw material. At the marketing stage, whether the biofuel can be sold in the gas station or acknowledged by the consumers remains a problem to be solved. Therefore, giving considerations to the characteristics of value chain at different stages is the important premise for formulating biofuel production policies. Correspondingly, analyzing the policy tools from the perspective of value chain is extremely important.

\section{Content analysis results}

For a start, the content analysis unit of the policy tools is encoded. There are 67 policy provisions, in which codes 22-5-4, 21-4-2 and 29-8-5 include two basic policy tools; code $22-5-4$ is both scientific information support and education; 21-4-2 is financial support and tax preference; 29-8-5, is tax preference and fund input, correspondingly.

In general, the policy provisions directly associated with waste cooking oil refining biofuel account for total policy provisions of $26.15 \%$.Among the indirect policies, provisions of waste collection and disposal account for $23.08 \%$, and biofuel research and development, $50.77 \%$, ranking first amongst all the policy tools. Obviously, current policy formulation does not couple the waste cooking oil collection and disposal with the biofuel production.
From the perspective of policy numbers' evolution, the policy numbers in 1992 were 3, and declined in 1993-2000. The numbers showed a trend of increase from 2001, amounting to 12 in 2010. In terms of institutions issuing policies, the policy numbers issued by a single department are remarkably more than those issued by two or more departments (see Fig. 1), which indicate the weak collaboration of Ministry of Commerce, Food \& Drug Administration, Industrial and Commercial Administration Bureau, Ministry of Finance and other departments. Additionally, though the issuing entities of partial polices are different, the issuing contents are similar. For example, 7-3-3 and 10-2-2 are respectively issued by Ministry of Health and Industrial and Commercial Administration Bureau. However, both policy contents relate to storage and disposal of wastes, showing no clear responsibilities division of functional departments.

\subsection{Analysis on basic policy tools}

Table 2 presents basic policy tools of waste cooking oil refining biofuel. The numbers of environment-typed policies rank the first, accounting for $71.64 \%$ of total policy provisions; followed by supply-typed tools, accounting for $25.37 \%$. Demand-typed policies have the least proportion $2.99 \%$. As can be seen in Table 2, regulation and target planning have the highest proportion, $34.33 \%$ and $22.39 \%$ respectively. The reason for frequent application of regulation and target planning lies in the weak enforcement of policies or the failure to fulfill the expectations. For instance, there are many clauses on the regulation of wastes recycling and disposal. According to the Section 8 of Frontier Health and Quarantine Law of the People's Republic of China (Chapter 2), there should be available facilities for disinfection, sewage discharge, garbage storage and wastes for the food production unit. Then, Management Regulations on Waste Cooking Oil in Food Production and Business Operation Entities (2002) points out that the waste oil arising from the production and operation of food production \& operation unit should be collected immediately and 
stored in the closed containers specially labeled with the words 'special purpose for waste oil'. Nevertheless, Food Safety Law of the People's Republic of China and Measures for the Administration of Food Circulation Permits were issued in 2009 and there were similar regulations. It is the same for the provisions of bio-liquid fuel production. According to Middle and Long Term Programme of Renewable Energy Development issued in 2007, the government should attach importance to bio-liquid fuel techniques, which have a favorable development prospect. Also, China's National Climate Change Programme issued in the same year proposed the vigorous efforts should be paid to promote the development of bio-liquid fuel. Under the Guiding Catalogue of Industrial Structure Adjustment (2011), government shall encourage the exploitation and application of non-food biomass fuels like biodiesel, etc. Apparently, there are lack of specific and operational policies for the aforementioned policy documents.

The proportion of the tax preference is $8.96 \%$, the same with that of infrastructure construction in the supply-typed policy tools. The proportion of the financial support and fund input is $4.47 \%$ and $2.99 \%$ respectively, while for the intellectual property protection, outsourcing and international cooperation, the proportion of each is only $1.49 \%$. Clearly, China's government focuses on the policy tools at the levels of strategy, regulation and administration, instead of economy, which suggests that producing biofuel with waste cooking oil is more reliant on government strong promotion rather than the market-based measures. Through the analysis of demand-typed policies, it indicates that biofuel produced by waste cooking oil is confronted with many uncertainties. Thus, the demand-typed polices need improvement to stabilize the market.

\subsection{Analysis on enterprise value chain}

We make further analysis on the statistics of the basic policy tools from the perspective of value chain dimension (see Table 3). The policy numbers at waste recycling and disposal stage account for $29.85 \%$, ranking the first throughout the four stages of value chain, followed by policy numbers for production stage $(28.36 \%)$, and then the least policy tools for consumption stage, $10.45 \%$. Additionally, codes [6-3-13], [13-2-3], [14-3], [19-4-2], [29-5] and [30-4-1] represent target planning policy tools without aiming at specific stage of the value chain. These policy tools also take up a small proportion.

The statistical results provide the evidence that China's government focuses more on the disposal of waste cooking oil and biomass production, and less on biofuel consumption. Essentially, international experience proved the effective integration of value chain by formulating biofuel consumption policies. For instance, Brazil, one of the earliest countries planning renewable energy, made exerted efforts to promote the consumption of biofuel. According to ethanol policies in Brazil, $11.85 \%$ of federal tax should be paid for consuming regular gasoline and ethanol; however, as for the state tax, only $12 \%$ shall be conducted for consuming ethanol and $25 \%$ for regular gasoline. In terms of biodiesel, Brazil unveiled Biodiesel Production and Use Program in 2004, announcing the proportion of biodiesel and regular diesel in blend fuel was $2 \%$ and $98 \%$ respectively from January 2008. By 2013, the mixing ratio of biodiesel will be pushed up to $5 \%$. Remarkable effects on consumption policies of ethanol and biodiesel in Brazil have been realized. Currently, the proportion of biomass in energy consumption structure in Brazil exceeds $30 \%$. Likewise, India promoted a plan for ethanol-blended petrol plan in major sugar-producing states such as Maharashtra and Uttar Pradesh et al. in 2000. The next year ethanol blended gasoline was sold in 300 retail outlets. Upon successful implementation of plan for ethanol-mixed gasoline, Ministry of Petroleum and Natural Gas extended the plan to other states in India.

Compared to Brazil and India, Chinese government supported the consumption of biodiesel in the policies of [24], [22-3-2], [29-6-2], [23-6], [29-8-3], [32-16] and [32-31]. Nevertheless, we found that only [24] 
among the aforementioned polices is directly associated with producing biofuel with waste cooking, while others are indirect biofuel polices. Moreover, the tax policy [23-6] has a guiding significance, but remains sketchy.

In summary, China lays emphasis on scientific information support, infrastructure construction, target planning at the stage of $\mathrm{R} \& \mathrm{D}$, and regulation at the stage of waste recycling of disposal. For the stage of consumption, the government stresses target planning and regulation. Clearly, the government only attaches importance to the economic policy tools at the production stage. At other three stages, the government highlights establishing policy tools from the aspects of administrative orders, regulations and strategies. Especially, China makes vigorous regulatory efforts to control the back flow of waste cooking to the dining table rather than employ market-oriented measures at the stage of waste recycling and disposal. The experience of a few developed countries suggests that placing conduction mechanism in the coequal and significant position with regulation will help to control the flow direction of waste cooking oil. For example, the US and Japan have made great advances in producing biofuel from waste cooking oil. In the US, The Solid Waste Disposal was passed as early as 1965 (subsequently was amended and renamed The Conservation \& Recovery Act), and followed by The Superfund Amendments and Reauthorization Act of 1986, The Pollution Prevention Act of 1990, and others; these regulated the recycling and disposal of waste. The Resources Conservation \& Recovery Act extended a simple clean-up work of waste management to further include comprehensive planning, combined recycling, reducement and resource recovery. For the serious offenders, the criminal action could be taken, which involved huge fines and sentence. The Pollution Prevention Act of 1990 regulated resource use reduction, clean energy efficiency improvement and waste recycling, and proposed the pollution prevention policies in substitution for pollution control policies. As for catering service supervision, the US effectively prevented the waste cooking oil back to the dining-table by means of the Hygiene License system, day-to-day supervision system and risk ranking management system.

In addition to strict regulation, the US has employed conduction policies to stimulate the biofuel consumption. Energy Policy of Act explicitly provided for the use of biodiesel as an alternative vehicle fuel. In 2003, the US Senate Finance Committee passed a biodiesel tax incentive, which dictated that for every $1 \%$ biodiesel added, a 1 cent sales tax could be exempted, up to $20 \%$. With the combination of regulation and incentive policies, waste cooking oil has become an important raw material for biofuel production.

There are three features of the waste disposal and reutilization policy in Japan:

(1) Lay stress on the regulation of waste disposal. The Waste Disposal Act amendments specified the provisions for waste disposal matters of banned oils and severe punishment for violators. In 2001, Japan enacted Food Waste Recyling Law, whereby catering services have an obligation to recycle waste and to curb waste generation. Moreover, restaurant could be ordered to stop business in cases of purchasing waste cooking oil or selling the kitchen wastes to individuals privately.

Attach importance to the regulation of consumers. According to the fifth provision of The Law for the Promotion of Effective Utilization of Recycled Resources, consumers should make efforts to promote the reutilization of recyclable resources.

(3) Emphasize the incentives of promoting waste cooking oil supply and biofuel sales. To channel the flow of wastes, it provides for offering professional recycling companies with high price subsidies upstream of value chain, which is another form of subsidy. Downstream of the value chain, the biofuel price is slightly less than that of gasoline, strongly promoting the biofuel consumption. Thus, big profits and strict regulations can result in the effective utilization of waste cooking oil as a resource. 
To reduce the uncertainty of waste cooking

Compared with the US and Japan, regulatory policies are not strict in China. Furthermore, China provides less subsidies and preferential taxation for the producing biofuel with waste cooking oil, and no subsidies and preferential taxation for the biofuel consumption (see Table 4).

\section{Conclusions}

We analyze the policies of biofuel produced by waste cooking oil and draw following conclusions:

(1) To make clear the responsibility of functional department, and promote the collaboration of policy issued departments. China should further define the responsibility of sectors related to waste cooking oil refining biofuel on the basis of Opinions on Strengthening Management of Kitchen Waste and Drainage Oil (2010). Quality Control Bureau assumes the responsibilities of waste oil regulation during the food processing; Municipal Department is responsible for monitoring the recycle of kitchen waste, standardizing the collection, transport and disposal. The Health Sectors should improve the test methods by cooperating with relative departments. For the Public Security Bureau, it should investigate the suspected waste cooking oil crime cases. Ministry of Commerce, Food \& Drug Administration and Industrial and Commercial Administration Bureau are all involved in the regulation of food and beverage services. According to the current policies provisions, their responsibility have overlapping areas and the provisions need more modifications. Moreover, as current policies are mainly issued by a single sector, it is necessary for China to strengthen the coordination of institutions.

(2) To reduce the overuse of environment policies and increase the market-oriented policy tools. Due to the excessiveness of goal planning and regulatory control policies, China may lessen the repeated policies, as well as develop a detailed implementation measures. oil refining biofuel, China may formulate demand policies such as government procurement and financial support for intermediary companies' recycling kitchen waste.

In view of the scarce policies of investment funds, financial support, outsourcing and other market-oriented initiatives, the government should address the flow direction of waste cooking oil. For example, China may develop policies to facilitate finance and provide tax preference; increase the price subsidies of raw materials, enabling the formal businesses have an advantage of raw material price over that of illegal ones.

(3) To attach importance to policy tools in the consumption stage, and to strengthen the value chain integration of waste cooking oil refining biofuel. For promoting the consumption of biofuels, China may consider two types of policies: firstly, enforce the sales regulation such as setting purchasing quotas, or requiring PetroChina, Sinopec and other state-owned companies to purchase finished goods of biofuel enterprises. Moreover, China can establish stipulating the composition of bio-liquid, oil and conventional diesel. Secondly, develop innovative sales policies such as preferential consumption tax. With the two types of policies, China may reduce the demand uncertainty of biofuel.

(4) To develop strict penal policies and increase the costs of waste cooking oil flowing back to the dining table. The penal policies need modification with regards to not only the relative departments involved but also the catering service providers and the producers of illegal re-processed cooking oil. As it may not be enough just to clarify the law with respect to government agencies, the state should shift the burden of responsibility more to departments and penalize those departments that fail to perform adequate checks. As for caterers and illegal producers, harsher penalties including heavy fines and imprisonment should be mandatory. 


\section{Acknowledgements}

This study is funded by National Social Science Foundation of China (Project no. 08\&ZD046), Humanities and Social Science Foundation of Ministry of Education (Project no. 10YJC630381), Jiangsu Postdoctoral Foundation (Project no. 1010045C), and the Priority Academic Program Development of Jiangsu Higher Education Institutions. This paper is also funded by launched project of National Natural Science Foundation of China (Project no. 71173116), National Natural Science Foundation of China (Project no. 71140014) and The National Soft Science Research Program (Project no. 2011 GXQ4B025).

\section{References}

[1] Zhao JH. Holding a press conference, discloser of waste cooking oil corrected himself for the pressure [EB/OL].http://medicine.people.com.cn/BIG5/11211 726.html.

[2] Yu H, Yu LW, Cao LB. Management of waste cooking oil and countermeasures. Pollution Control Technology 2010; 23(4): 44-45.

[3] Ni SL, Wang SY, Liang SY. Analysis on the industrialization of kitchen waste disposal. Energy Research and Information 2011; 27(1): 7-12.

[4] Ji Z. Current situation and countermeasures of kitchen waste management in Tianjin, China. Environmental Health Engineering 2011; 19(1): 25-29.

[5] Wu SX, Dong JY, Guan CY. Progress in biodiesel research and industrialization development strategy. Grain Processing and Food Machinery 2006; 2: 56-59.

[6] Yang DL, Ni JM. Research on the development of biodiesel technology and industrialization direction. Agriculture Equipment and Vehicle Engineering 2007; 4: 6-9.

[7] Li XB, Wang JG. Feasibility analysis on development of biodiesel and industrialization suggestions. Hubei Agriculture Science 2008; 47(11): 1364-1368

[8] Ji XY. Research on biodiesel development and its industrialization. Price Monthly 2009; 8: 26-28

[9] Zhang XL et al. Analysis on resource and technology potential of bio-liquid fuel development in China. China Energy 2009;31(3): 10-12
[10] Ji X. Research on the technology and policies of biodiesel produced by kitchen waste. Energy of China, 2011; 33(9): 36-39.

[11] Wang Q, Wang LS, Zheng YH. Time for commercializing non-food biofuel in China. Renewable and Sustainable Energy Reviews 2011; 15(1): 621-629.

[12] Tsai WT, Lin CC, Yeh CW. An analysis of biodiesel fuel from waste edible oil in Taiwan. Renewable and Sustainable Energy Reviews 2007;11: 838-857.

[13] Alexey OP, Arthur PJ, Peter O. Stagnating liquid biofuel developments in Russia: Present status and future perspectives. Energy Policy 2010; 38: 3320-3328.

[14] Giovanni S, Martin B, Claudia K. An overview of biofuel policies across the world. Energy Policy 2010; 38(11): 6977-6988.

[15] Grasman SE, Sadashivam S. Implementation policy considerations for achieving year-round operability of biodiesel programs. Biomass and Bioenergy 2012; 39: 439-448.

[16] Basheer Hasan Diya'uddeen, A.R. Abdul Aziz, W.M.A.W. Daud, M.H. Chakrabarti. Performance evaluation of biodiesel from used domestic wasteoils: A review. Process Safety and Environmental Protection 6 March 2012; Available online

[17] Hang TJ et al. An overview of biodiesel industrialization experience. Sichuan Forestry Science and Technology 2007; 28(6): 27-30.

[18] Ning SJ. Review on the industrialization of biodiesel in South Korea. Modern Chemical Industry 2008; 28(9): 82-83.

[19] Tobias W et al. Biofuel support policies in Europe: lessons learnt for the long way ahead. Renewable and Sustainable Energy Reviews 2009;13: 789-800.

[20] Zhang CF, Dang XY. Public Management. Beijing. Renmin University of China Press 2001.

[21] Chen ZM. Research on government tools and improvement of government management. Chinese Administration 2004; 6:43-48.

[22] Tao XR. Public Policy. Dalian: Dongbei University of Finance \& Economics Press 2006.

[23] Rothwell R., Zegveld W. Reindusdalization and Technology. Logman Group Limited 1985. 